\title{
SISTEM PENDUKUNG KEPUTUSAN PEMBERIAN DANA PENGEMBANGAN USAHA AGRIBISNIS PEDESAAN (PUAP) KEPADA GAPOKTAN MENGGUNAKAN METODE SIMPLE ADDITIVE WEIGHTING (SAW)
}

\author{
Amiruddin \\ amier.76@gmail.com \\ Fakultas IImu Komputer Universitas Ichsan Gorontalo
}

\begin{abstract}
Abstrak
PUAP bertujuan untuk mengurangi kemiskinan, pengangguran dan kesenjangan pembangunan antar wilayah dan sektor. BP4K sebagai pembina gapoktan mempunyai tugas untuk memberdayakan aktifitas gapoktan dan salah satunya melalui bantuan dana PUAP. Proses penyeleksian penerima bantuan dana PUAP terdapat masalah yang dihadapi, diantaranya sulitnya menentukan Gapoktan yang layak mendapatkan bantuan dana PUAP dikarenakan banyaknya proposal permintaan dana yang masuk dan banyaknya kriteria yang digunakan sehingga membutuhkan ketelitian dalam proses pengolahan datanya, untuk itu diperlukan sebuah sistem pendukung keputusan. Metode yang digunakan adalah SAW. Berdasarkan hasil penelitian sistem tersebut dapat membantu pihak pengambil keputusan dalam menentukan alternatif (gapoktan) terbaik untuk menerima Dana PUAP. Hal ini dibuktikan dengan hasil pengujian yang dilakukan dengan metode white box testing dan basis path testing yang menghasilkan nilai yang sama, sehingga didapat bahwa logika flowchart perhitungan, penilaian dan perankingan yang benar dan berdasarkan pengujian black box rancangan perangkat lunak telah terpenuhi dengan hasil sesuai dengan rancangan.
\end{abstract}

Kata kunci : Gapoktan, SAW, PUAP, MADM.

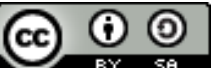

ILKOM Jurnal IImiah work is licensed under a CCA-SA 4.0 International License.

\section{Pendahuluan}

Program Pemberdayaan Usaha Agribisnis Perdesaan (PUAP) dilaksanakan oleh petani (pemilik penggarap atau penggarap), buruh tani dan rumah tangga tani miskin di perdesaan melalui koordinasi Gapoktan sebagai lembaga yang dimiliki dan dikelola oleh petani. Kementerian Pertanian sejak Tahun 2008-2014 telah melaksanakan Program Pengembangan Usaha Agribisnis Perdesaan (PUAP) dibawah koordinasi Program Nasional Pemberdayaan Masyarakat Mandiri (PNPM-Mandiri) dan berada dalam kelompok program pemberdayaan masyarakat. Pelaksanaan Pengembangan Usaha Agribisnis Perdesaan (PUAP) Tahun 2015 mengacu kepada pola dasar yang ditetapkan dalam Peraturan Menteri Pertanian Nomor 06/Permentan/OT.140/2/2015 tentang Pedoman Pengembangan Usaha Agribisnis Perdesaan(PUAP) Tahun 2015, untuk meningkatkan keberhasilan penyaluran dana BLM-PUAP kepada Gapoktan dalam mengembangkan usaha produktif petani. Strategi dasar yang dilakukan melalui pemberdayaan masyarakat, optimalisasi potensi agribisnis, fasilitasi modal usaha petani kecil, penguatan dan pemberdayaan kelembagaan [1].

Agribisnis merupakan salah satu usaha atau bisnis yang menitikberatkan pada usaha pertanian atau bidang lain serupa atau segala usaha yang berpacu pada usaha pangan dan beberapa sektor yang menyerupainya. Usaha agribisnis padesaan yang dikembangkan antara lain : pengolahan hasil, padi sawah, tanaman hias dan lahan kering. Pemberian Dana PUAP kepada Gapoktan (gabungan kelompok tani) yang ada di Kota Gorontalo didasarkan pada kriteria yang telah ditentukan oleh BP4K (Badan Pelaksana Penyuluhan Pertanian Perikanan dan Kehutanan) sehingganya hal ini yang menjadi permasalahan bagi pihak BP4K. Dana PUAP diberikan sekali setiap tahunnya, dimana jumlah Gapoktan saat ini di Kota Gorontalo berjumlah 50 Gapoktan sementara yang akan diberikan Dana PUAP hanya 3 Gapoktan [2], sehingga timbul permasalahan sulitnya pihak BP4K dalam menyeleksi Gapoktan yang berhak mendapatkan bantuan dana PUAP dikarenakan banyaknya proposal permintaan dana yang masuk dan banyaknya kriteria pemilihan yaitu luas lahan, jumlah poktan, keaktifan kepengurusan, SDM pengelola dan kualitas produksi, sehingga membutuhkan ketelitian dalam proses pengolahan datanya agar Gapoktan yang terpilih adalah benar-benar Gapoktan yang layak menerima bantuan, untuk itu diperlukan sebuah sistem pendukung keputusan untuk membantu pihak BP4K dalam pengambilan keputusan. 
Adapun metode yang digunakan dalam sistem pendukung keputusan ini adalah metode Simple Additive Weighting (SAW), metode ini dipilih karena metode ini menentukan nilai bobot untuk setiap atribut, kemudian dilanjutkan dengan proses perankingan yang akan menyeleksi alternatif terbaik [3], dalam hal ini alternatif yang dimaksud adalah yang berhak mendapatkan dana PUAP kepada Gapoktan, dengan metode perankingan tersebut, diharapkan penilaian akan lebih tepat karena didasarkan pada nilai kriteria dan bobot yang sudah ditentukan sehingga akan mendapatkan hasil yang lebih akurat terhadap siapa yang berhak mendapatkan bantuan dana PUAP nantinya.

\section{Landasan Teori}

\subsection{Pengertian Sistem Pendukung Keputusan}

Konsep Sistem Pendukung Keputusan (SPK) atau Decision Support Systems (DSS) pertama kali diungkapkan pada awal tahun 1970-an oleh Michael S. Scott Morton dengan istilah Management Decision Systems

Morton, et al mendefinisikan DSS sebagai "Sistem Berbasis Komputer Interaktif, yang membantu para pengambil keputusan untuk menggunakan data dan berbagai model untuk memecahkan masalah-masalah yang tidak terstruktur". [4]

Menurut Alter, DSS merupakan sistem informasi interaktif yang menyediakan informasi, pemodelan dan pemanipulasian data. Sistem digunakan untuk membantu pengambilan keputusan dalam situasi yang semi terstruktur dan situasi yang tidak terstruktur, dimana tak seorang pun tahu secara pasti bagaimana keputusan seharusnya dibuat. [5]

DSS (Decision Support Systems) biasanya dibangun untuk mendukung solusi atas suatu masalah atau untuk mengevaluasi suatu peluang. DSS yang seperti itu disebut aplikasi DSS. Aplikasi DSS digunakan dalam pengambilan keputusan. Aplikasi DSS menggunakan CBIS (Computer Based Information Systems) yang fleksibel, interaktif dan dapat diadaptasi yang dikembangkan untuk mendukung solusi atas masalah manajemen spesifik yang tidak terstruktur.

Pada dasarnya SPK ini merupakan pengembangan lebih lanjut dari Sistem Informasi Manajemen Terkomputerisasi (Computerized Manajement Information Systems), yang dirancang sedemikian rupa sehingga bersifat interaktif dengan pemakainya. Sifat interaktif ini dimaksudkan untuk memudahkan integrasi antara berbagai komponen dalam proses pengambilan keputusan, seperti prosedur, kebijakan, teknik analisis, serta pengalaman dan wawasan manajerial guna membentuk suatu kerangka keputusan yang bersifat fleksibel

\subsection{Komponen-Komponen Sistem Pendukung Keputusan}

Menurut Turban [4], Sistem Pendukung Keputusan terdiri dari 4 subsistem yaitu :

1. Manajemen Data, meliputi basis data yang berisi data-data yang relevan dengan keadaan dan dikelola oleh perangkat lunak yang disebut Database Management System (DBMS).

2. Manajemen Model berupa sebauh paket perangkat lunak yang berisi model-model finansial, statistik, management science, atau model kuantitatif yang menyediakan kemampuan analisa dan perangkat lunak manajemen yang sesuai.

3. Subsistem Dialog atau komunikasi, merupakan subsistem yang dipakai oleh user untuk berkomunikasi dan memberi perintah (menyediakan user interface).

4. Manajemen Knowledge yang mendukung subsistem lain atau berlaku sebagai komponen yang berdiri sendiri.

\subsection{Konsep Dasar Multiple Attribute Decision Making (MADM)}

MADM adalah salah satu metode yang digunakan untuk mencari alternatif optimal dari sejumlah alternatif dengan kriteria-kriteria tertentu. Inti dari Multiple Attribute Decision Making (MADM) adalah menentukan nilai bobot untuk setiap atribut/kriteria, yang kemudian dilanjutkan dengan proses perankingan yang akan menyeleksi alternatif yang sudah diberikan. Pada dasarnya, ada 3 (tiga) pendekatan untuk mencari nilai bobot atribut, yaitu pendekatan subyektif, pendekatan obyektif dan pendekatan integrasi antara subyektif \& obyektif. Masing-masing pendekatan memiliki kelebihan dan kelemahan. Pada pendekatan subyektif, nilai bobot ditentukan berdasarkan subyektifitas dari para pengambil keputusan, sehingga beberapa faktor dalam proses perankingan alternatif bisa ditentukan secara bebas. Sedangkan pada pendekatan obyektif, nilai bobot dihitung secara matematis sehingga mengabaikan subyektifitas dari pengambil keputusan [3].

Ada beberapa metode yang dapat digunakan untuk menyelesaikan masalah MADM antara lain [3] :

a. Simple Additive Weighting Method (SAW)

b. Weighted Product (WP) 
c. Electre

d. Technique for Order Preference by Similarity to Ideal Solution (TOPSIS)

e. Analytic Hierarchy Process (AHP)

\subsection{Simple Additive Weighting (SAW)}

Metode Simple Additive Weighting (SAW) sering juga dikenal istilah metode penjumlahan terbobot. Konsep dasar metode SAW adalah mencari penjumlahan terbobot dari rating kinerja pada setiap alternatif pada semua atribut. Metode SAW membutuhkan proses normalisasi matriks keputusan $(\mathrm{X})$ ke suatu skala yang dapat diperbandingkan dengan semua rating alternatif yang ada.

Normalisasi dapat dihitung sebagai berikut [3] :

$$
r_{i j}= \begin{cases}\frac{x_{i j}}{\operatorname{Max}_{i}} & j i k a \text { jadalah atribut keuntungan (benefit) } \\ \frac{\operatorname{Min}_{i} x_{i j}}{x_{i j}} & \text { jika jadalah atribut biaya (cost) }\end{cases}
$$

Dimana :

$r_{i j} \quad$ : Rating kinerja ternormalisasi

Maxi $_{i}$ : Nilai maksimum dari setiap baris dan kolom

$\mathrm{Min}_{\mathrm{i}}$ : Nilai minimum dari setiap baris dan kolom.

$\mathrm{X}_{\mathrm{ij}} \quad$ : Baris dan kolom dari matriks

$r_{i j} \quad$ : adalah rating kinerja ternormalisasi dari alternatif $A_{i}$ pada atribut $C_{j} ; i=1,2, \ldots, m$ dan $j=1,2, \ldots, n$.

Nilai preferensi untuk setiap alternatif $\left(\mathrm{V}_{\mathrm{i}}\right)$ diberikan sebagai:

Dimana :

$$
V_{i}=\sum_{j=1}^{n} w_{j} r_{i j}
$$

$V_{i} \quad$ : Nilai akhir dari alternative

$\mathrm{W}_{\mathrm{i}} \quad$ : Bobot yang telah ditentukan

$\mathrm{r}_{\mathrm{ij}} \quad$ : Normalisasi matriks

Nilai $V_{i}$ yang lebih besar mengindikasikan bahwa alternatif $A_{i}$ lebih terpilih. adalah:

Menurut Kusumadewi [3]. Langkah - langkah penelitian dalam menggunakan metode SAW,

1. Menentukan kriterian-kriteria yang akan dijadikan acuan dalam pengembilan keputusan, yaitu $\mathrm{C}_{\mathrm{i}}$.

2. Menentukan rating kecocokan setiap alternatif pada setiap kriteria.

3. Membuat matriks keputusan berdasarkan kriteria $\left(C_{i}\right)$, kemudian melakukan normalisasi matriks berdasarkan persamaan yang disesuaikan dengan jenis atribut (atribut keuntungan maupun atribut biaya) sehingga diperoleh matriks ternormalisasi $R$.

Hasil akhir diperoleh dari setiap proses perangkingan yaitu penjumlahan dari perkalian matriks ternormalisasi $R$ dengan vector bobot sehingga diperoleh nilai terbesar yang dipilih sebagai alternatif terbaik $\left(A_{i}\right)$ sebagai solusi.

\subsection{Siklus Hidup Pengembangan Sistem}

Menurut Jogiyanto [6]. Proses pengembangan sistem melewati beberapa tahapan dari mulai sistem itu direncanakan sampai dengan sistem tersebut diterapkan, dioperasikan dan dipelihara. Bila operasi yang sudah dikembangkan masih timbul kembali permasalahan-permasalahan yang tidak dapat diatasi dalam tahap pemeliharaan, maka perlu dikembangkan kembali suatu sistem untuk mengatasinya dan proses ini kembali ke tahap yang pertama, yaitu tahap perencanaan sistem. Siklus ini disebut dengan siklus hidup suatu sistem (systems life cycle). Daur atau siklus hidup dari pengembangan sistem merupakan suatu bentuk yang digunakan untuk menggambarkan tahapan utama dan langkah-langkah didalam tahapan tersebut dalam proses pengembangannya. Berikut langkah-langkah yang digunakan : 


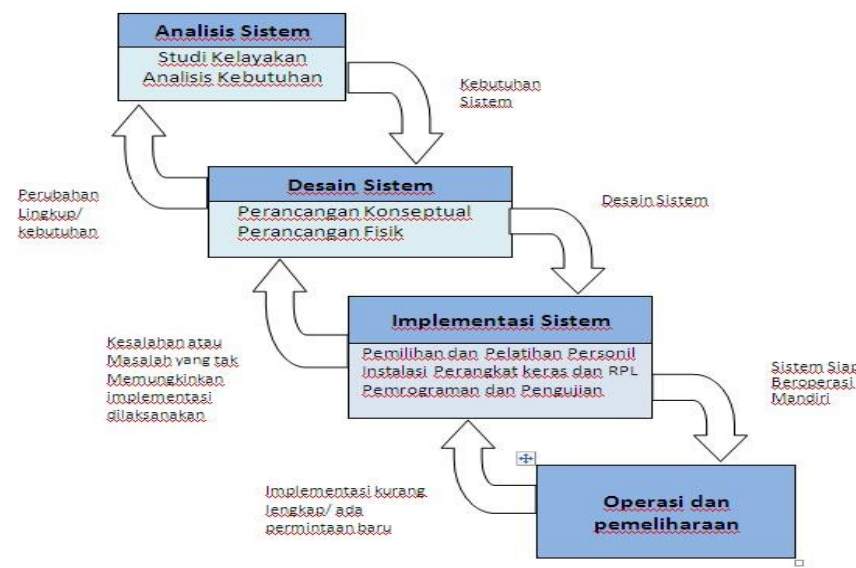

Gambar 1. Siklus Hidup Pengembangan Sistem

\subsection{Teknik Pengujian Sistem}

Pengujian sistem adalah elemen kritis dari jaminan kualitas perangkat lunak dan mempresentasikan kajian pokok dari spesifikasi, desain, dan pengkodean. Tujuan dari pengujian ini adalah diharapkan dengan minimal tenaga dan waktu untuk menemukan berbagai potensi kesalahan dan cacat.Harus didasarkan pada kebutuhan berbagai tahap pengembangan, desain dan dokumen lain atau program yang dirancang untuk menguji struktur internal, dan menggunakan contoh-contoh ini untuk menjalankan program untuk mendeteksi kesalahan.Pengujian sistem informasi harus mencakup pengujian perangkat lunak, pengujian perangkat keras dan pengujian jaringan.Pengujian hardware, jaringan pengujian berdasarkan indikator kinerja spesifik yang akan digunakan di sini pengujian lebih jauh adalah pengujian perangkat lunak [7].

\section{a. White Box}

Pengujian white-box (glass box), adalah metode desain test case yang menggunakan struktur kontrol desain prosedural untuk memperoleh test case. Dengan menggunakan metode pengujian white-box, perekayasa sistem dapat melakukan test case untuk memberikan jaminan bahwa :

1. Semua jalur independen pada suatu modul ditelusuri minimal 1 (satu) kali.

2. Semua jalur keputusan logis True/False dilalui.

3. Semua loop dieksekusi pada batas yang tercantum dan batas operasionalnya.

4. Struktur data internal digunakan agar validitas terjamin.

Pengujian white-box bisa dilakukan dengan pengujian basis path, metode ini merupakan salah satu teknik pengujian struktur kontrol untuk menjamin semua statemen dalam setiap jalur independen program dieksekusi minimal 1 kali dan tidak menjumpai error message. Perhitungan jalur independen dapat dilakukan melalui metrik Cyclomatic Complexity. Sebelum menghitung nilai Cyclomatic Complexity, harus diterjemahkan desain prosuderal ke grafik alir, kemudian dibuat flow graphnya [7]

\section{b. BlackBox}

Pengujian Black-Box berusaha menemukan kesalahan dalam kategori :

1. Fungsi tidak benar atau hilang.

2. Kesalahan antar muka.

3. Kesalahan pada struktur data (pengaksesan basis data).

4. Kesalahan inisialisasi dan akhir program.

5. Kesalahan performasi.

Pengujian ini berfokus pada persyaratan fungsional perangkat lunak dan merupakan komplemen dari pengujian White-Box. Hal ini dapat dicapai melalui :

a. Pengujian Graph-based: dimulai dengan membuat grafik sekumpulan node yang mempresentasikan objek (misal New File, Layar baru dengan atributnya), link (hubungan antar objek), node-weight (misal nilai data tertentu seperti atribut layar, perilaku), dan link-weight (karakteristik suatu link, misal menu select).

b. Equivalence Partitioning: membagi domain input untuk pengujian agar diperoleh kelas-kelas kesalahan (misal kelompok data karakter, atau atribut yang lain).

c. Analisis Nilai Batas: pengujian berdasarkan nilai batas domain input.

d. Pengujian Perbandingan: disebut juga pengujian back-to-back yang diterapkan pada pada suatu versi perangkat lunak atau perangkat lunak redundan untuk memastikan konsistensinya 


\section{Metode}

Adapun metode atau cara penelitian yang dilakukan dapat diuraikan sebagai berikut:

a. Tahap Analisis : pada tahap ini dilakukan analisis sistem yang terdiri dari analisis sistem dan kebutuhan sistem

b. Tahap Desain : pada tahap ini dilakukan desain sistem yakni desain model, desain output, desain input, desain menu utama, dan desain database.

c. Tahap Produksi/Pembuatan : pada tahap ini dilakukan setelah tahap desain selesai. Dalam pembuatan sistem ini digunakan bahasa pemrograman Microsoft Visual Basic 6.0, Databasenya menggunakan MySQL dan Report atau laporan menggunakan Crystal Report 8.5.

d. Tahap Pengujian : tahap ini dilakukan setelah semua modul selesai dibuat, dan program dapat berjalan, dimana seluruh perangkat lunak, program tambahan, dan semua program yang terlibat dalam pembangunan sistem diuji untuk memastikan sistem dapat berjalan sesuai dengan rancangan atau belum. Pengujian sistem dilakukan dengan menggunakan data yang telah didapat pada tahap analisa sistem. Jika terjadi hal-hal yang tidak sesuai dengan yang diharapkan, kemudian dilakukan revisi atau perbaikan agar sistem tersebut dapat dioperasikan dengan baik dan siap untuk diiplementasikan. Pengujian yang dilakukan dengan teknik pengujian perangkat lunak yang telah ada yaitu pengujian White Box dan pengujian Black Box.

e. Tahap Implementasi : pada tahap ini dilakukan penerapan sistem pada kantor BP4K Kota Gorontalo.

\section{Hasil}

Berikut beberapa tampilan form dari aplikasi sistem pendukung keputusan yang sudah dibuat adalah sebagai berikut:

a. Form Input Penilaian Gapoktan

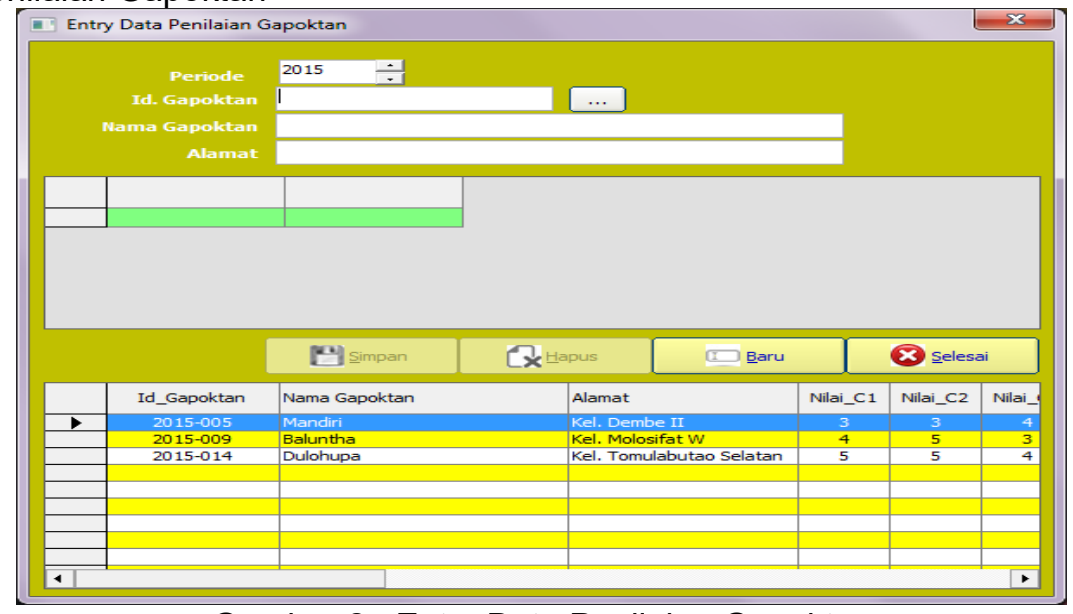

Gambar 2. Entry Data Penilaian Gapoktan

b. Tampilan Hasil Matriks Ternormalisasi

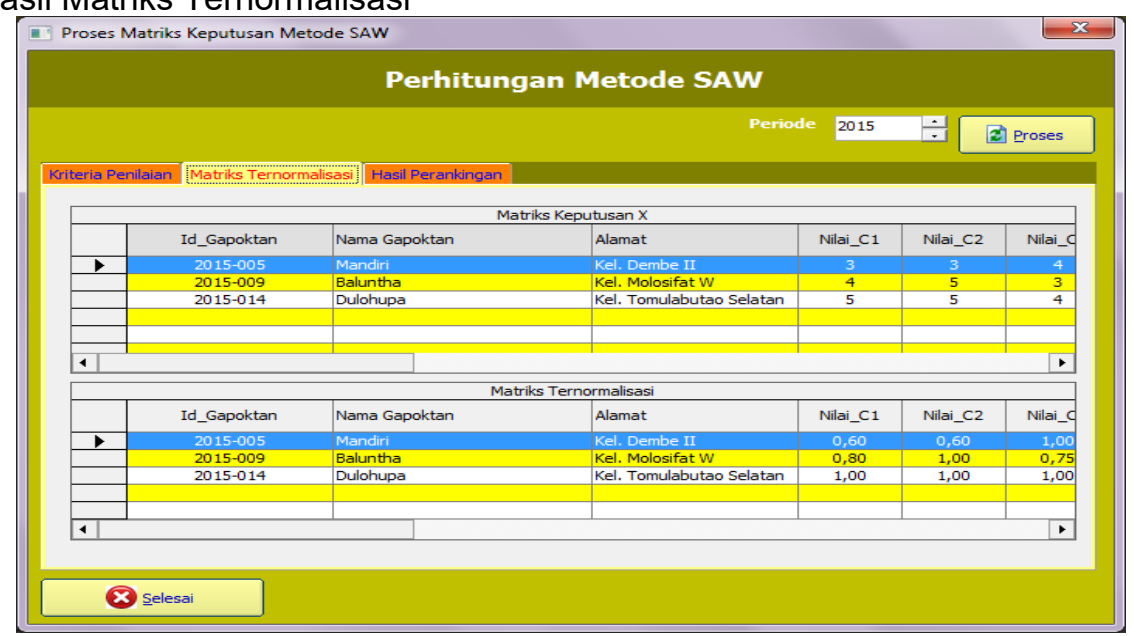

Gambar 3. Tampilan Hasil Matriks Ternormalisasi 
c. Tampilan Laporan Hasil Perhitungan Metode SAW

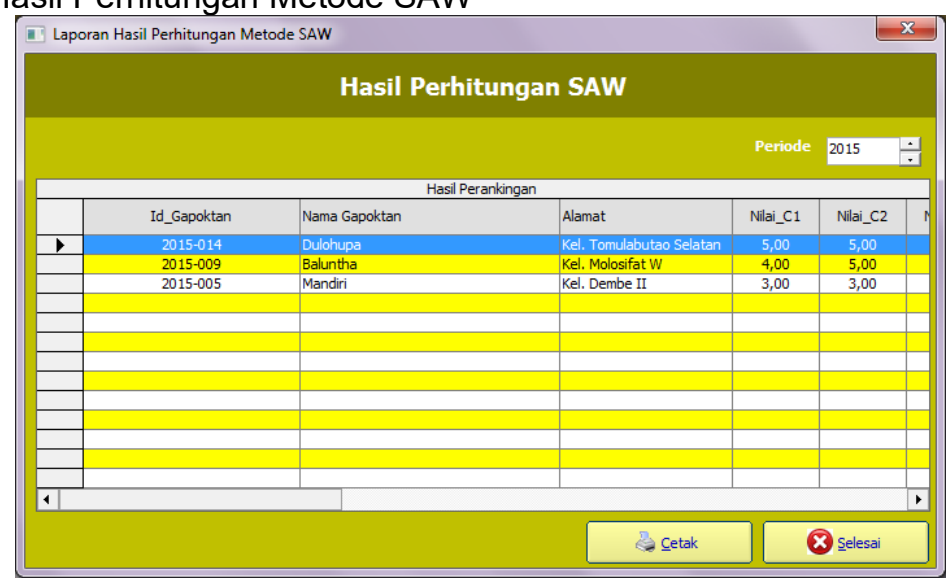

Gambar 4. Laporan Data Hasil Perhitungan Metode SAW

Berdasarkan hasil penelitian di atas, dilakukan perhitungan manual dengan mengambil 3 data sebagai sampel dalam perhitungan. Adapun data awal dan kriteri yang digunakan dalam perhitungan ini adalah sebagai berikut [2]:

Tabel 1. Kriteria Pemberian Bantuan

\begin{tabular}{|c|c|c|c|}
\hline Kode Kriteria & Nama Kriteria / Jenis Kriteria & Sub Kriteria & Bobot \\
\hline C1 & $\begin{array}{l}\text { Luas Lahan } \\
\text { Benefit }\end{array}$ & $\begin{array}{ll}- & >100 \mathrm{M}^{2} \\
- & 90-100 \mathrm{M}^{2} \\
- & 70-89 \mathrm{M}^{2} \\
- & 50-69 \mathrm{M}^{2} \\
- & <50 \mathrm{M}^{2}\end{array}$ & $\begin{array}{l}5 \\
4 \\
3 \\
2 \\
1\end{array}$ \\
\hline $\mathrm{C} 2$ & $\begin{array}{l}\text { Jumlah Poktan } \\
\text { Benefit }\end{array}$ & $\begin{array}{ll}- & >10 \text { Kelompok } \\
- & 9-10 \text { Kelompok } \\
- & 7-8 \text { Kelompok } \\
- & 5-6 \text { Kelompok } \\
- & <5 \quad \text { Kelompok }\end{array}$ & $\begin{array}{l}5 \\
4 \\
3 \\
2 \\
1\end{array}$ \\
\hline C3 & $\begin{array}{l}\text { Keaktifan Kepengurusan } \\
\text { Benefit }\end{array}$ & $\begin{array}{ll}- & \text { Sangat Aktif } \\
- & \text { Aktif } \\
- & \text { Kurang Aktif } \\
- & \text { Tidak Aktif }\end{array}$ & $\begin{array}{l}4 \\
3 \\
2 \\
1\end{array}$ \\
\hline $\mathrm{C} 4$ & $\begin{array}{l}\text { SDM Pengelola (Bidang IImu) } \\
\text { Benefit }\end{array}$ & $\begin{array}{ll}- & \text { Sesuai } \\
- & \text { Kurang Sesuai } \\
- & \text { Tidak Sesuai }\end{array}$ & $\begin{array}{l}3 \\
2 \\
1\end{array}$ \\
\hline C5 & $\begin{array}{l}\text { Kualitas Produksi } \\
\text { Benefit }\end{array}$ & $\begin{array}{ll}- & \text { Tinggi } \\
- & \text { Sedang } \\
- & \text { Kurang } \\
\end{array}$ & $\begin{array}{l}3 \\
2 \\
1\end{array}$ \\
\hline
\end{tabular}

Tabel 2. Nilai Alternatif Pada Setiap Kriteria

\begin{tabular}{cccccc}
\hline \multirow{2}{*}{ Alternatif } & \multicolumn{5}{c}{ Kriteria } \\
\cline { 2 - 6 } & C1 & C2 & C3 & C4 & C5 \\
\hline A1 & 3 & 3 & 4 & 3 & 3 \\
A2 & 4 & 4 & 3 & 3 & 2 \\
A3 & 5 & 5 & 4 & 3 & 2 \\
\hline
\end{tabular}

Sebagai sampel dalam perhitungan ini adalah A1 =Mandiri, A2=Baluntha , A3 =Dulohupa Untuk menyelesaikan kasus di atas dilakukan tahapan sebagai berikut :

Bobot Preferensi : $\mathrm{W}=(5,4,4,3,3)$ 


$$
X=\left[\begin{array}{l}
3,3,4,3,3 \\
4,4,3,3,2 \\
5,5,4,3,2
\end{array}\right]
$$

Pertama-tama dihitung terlebuh dahulumatriks keputusan ternormalisasi berdasarkan persamaan 1 , sebagai berikut :

$$
\begin{aligned}
& r_{11}=\frac{3}{\max \{3 ; 4 ; 5\}}=\frac{3}{5}=0,60 \\
& r_{21}=\frac{4}{\max \{3 ; 4 ; 5\}}=\frac{4}{5}=0,80 \\
& r_{31}=\frac{5}{\max \{3 ; 4 ; 5\}}=\frac{5}{5}=1 \\
& r_{12}=\frac{3}{\max \{3 ; 4 ; 5\}}=\frac{3}{5}=0,60 \\
& r_{22}=\frac{4}{\max \{3 ; 4 ; 5\}}=\frac{4}{5}=0,80 \\
& r_{32}=\frac{5}{\max \{3 ; 4 ; 5\}}=\frac{5}{5}=1 \\
& r_{13}=\frac{4}{\max \{4 ; 3 ; 4\}}=\frac{4}{4}=1 \\
& r_{23}=\frac{3}{\max \{4 ; 3 ; 4\}}=\frac{3}{4}=0,75
\end{aligned}
$$

$$
\begin{aligned}
& r_{33}=\frac{4}{\max \{4 ; 3 ; 4\}}=\frac{4}{4}=1 \\
& r_{14}=\frac{3}{\max \{3 ; 3 ; 3\}}=\frac{3}{3}=1 \\
& r_{24}=\frac{3}{\max \{3 ; 3 ; 3\}}=\frac{3}{3}=1 \\
& r_{34}=\frac{3}{\max \{3 ; 3 ; 3\}}=\frac{3}{3}=1 \\
& r_{15}=\frac{3}{\max \{3 ; 2 ; 2\}}=\frac{3}{3}=1 \\
& r_{25}=\frac{2}{\max \{3 ; 2 ; 2\}}=\frac{2}{3}=0,67 \\
& r_{35}=\frac{2}{\max \{3 ; 2 ; 2\}}=\frac{2}{3}=0,67
\end{aligned}
$$

Sehingga diperoleh Matriks Ternormalisasi R Sebagai Berikut :

$$
R=\left[\begin{array}{lllll}
0,6000 & 0,6000 & 1,0000 & 1,0000 & 1,0000 \\
0,8000 & 0,8000 & 0,7500 & 1,0000 & 0,6700 \\
1,0000 & 1,0000 & 1,0000 & 1,0000 & 0,6700
\end{array}\right]
$$

Persamaan perangkingan diperoleh berdasarkan persamaan 2 sebagai berikut :

$$
\begin{aligned}
& \mathrm{V} 1=(5)(0,60)+(4)(0,60)+(4)(1)+(3)(1)+(3)(1)=15,4 \\
& \mathrm{~V} 2=(5)(0,80)+(4)(0,80)+(4)(0,75)+(3)(1)+(3)(0,67)=15,21 \\
& V 3=(5)(1)+(4)(1)+(4)(1)+(3)(1)+(3)(0,67)=18,01
\end{aligned}
$$

Nilai terbesar ada pada $V_{3}(18,01)$ Sehingga alternatif $A_{3}$ adalah alternatif yang terpilih sebagai alternatif terbaik. Dengan kata lain Gapoktan Dulohupa yang berhak menerima dana PUAP, disusul Gapoktan A2 (Baluntha) dan A1 (Mandiri).

\section{Kesimpulan}

Berdasarkan hasil penelitian di atas dapat ditarik kesimpulan sebagai berikut :

1. Metode Simple Additive Weighting (SAW), dapat digunakan untuk pemberian bantuan dana PUAP kepada Gapoktan.

2. Sistem Pendukung Keputusan pemberian bantuan dana PUAP kepada Gapoktan dengan menggunakan metode Simple Additive Weighting (SAW) dapat digunakan untuk membantu pihak pengambil keputusan, khususnya pada kantor BP4K Kota Gorontalo.

\section{Daftar Pustaka}

[1] Kementerian Pertanian. 2011. Pedoman Umum Pengembangan Usaha Agribisnis Perdesaan. Jakarta: Kementerian Pertanian Republik Indonesia.

[2] BP4K. 2015. Panduan Seleksi Pemberian Dana PUAP 2015. Gorontalo

[3] Kusumadewi, dkk.,2006, Fuzzy Multi-Atribute Decision Making (Fuzzy MADM), Yogyakarta: Graha IImu

[4] Turban, dkk, 2005, Decision Support Systems and Intelligent Systems, Yokyakarta : Andi

[5] Kusrini, 2007, Konsep dan Aplikasi Sistem Pendukung keputusan, Yokyakarta: Andi.

[6] Jogiyanto, 2005, Analisa dan Desain Sistem Informasi : Pendekatan Terstruktur Teori dan Praktek Aplikasi Bisnis, Yokyakarta: Andi Offset

[7] Pressman, R.S. 2002.Rekayasa Perangkat Lunak: Pendekatan Praktis (Buku I), Yogyakarta : Andi. 